\title{
A JUSTIÇA NO PALCO DOS MEDIA: A CONSTRUÇÃO DISCURSIVA DOS JUÍZES DO MENSALÃO EM NARRATIVAS DE VEJA E ÉPOCA
}

\author{
Justice In The Media Stage: The Discursive Construction Of Mensalão Judges \\ In Narratives Of Veja And Época
}

Justicia En La Etapa De Los Media: La Construcción Discursiva De Los Jueces Del Mensalão En Las Narrativas De Veja Y Época

\author{
Bruno Bernardo de Araújo \\ Universidade Federal de Mato Grosso - FCA/UFMT \\ brrunoaraujo@gmail.com
}

\section{Resumo}

Este trabalho estuda um aspecto muito específico da relação entre os media e a justiça nas democracias do nosso tempo, qual seja, o modo como o jornalismo constrói, em suas narrativas, a imagem dos juízes, os principais atores da justiça, em coberturas que conferem grande visibilidade ao universo judicial. Como trabalho empírico, analisaremos como as duas principais revistas de informação do Brasil, Veja e Época, construíram a imagem dos juízes do Supremo Tribunal Federal durante os quatro meses de julgamento da Ação Penal 470, o popular processo do Mensalão, que aconteceu entre agosto e dezembro de 2012. A análise do corpus, constituído por 20 edições das revistas, será realizada por meio da aplicação de categorias da análise critica do discurso, com especial foco em ferramentas sistematizadas por Theo van Leeuwen e Norman Fairclough.

Palavras-chave: Justiça. Media. Discurso.

\begin{abstract}
This work studies an aspect very specific of relationship between media and justice in democracy, that is, how journalism builds, in their narratives, the image of judges, the main actors of justice, in coverage that give high visibility to the judicial universe. As empirical work, we analyze the two main information magazines in Brazil, Veja and Época, built the image of the judges of the Supreme Court during the judgement of the criminal action 470, the popular process of Mensalão. The analysis of the corpus, constituted by 20 publications of magazines, will be performed by the application of categories of critical discourse analysis, with particular focus on tools formuleted by Theo van Leeuwen and Norman Fairclough.
\end{abstract}

Key words: Justice. Media. Discourse

\section{Resumen}


En este trabajo se estudia un aspecto muy concreto de la relación entre los medios y la justicia en las democracias de nuestro tiempo, es decir, cómo el periodismo construye, en sus narrativas, la imagen de los jueces, los principales actores de la justicia. En el trabajo empírico, analisaremos como las dos principales revistas de información en Brasil, Veja y Época, construyeron la imagen de los jueces de la Corte Suprema durante los cuatro meses de juicio de la Acción Penal 470, el proceso Mensalão, que tuvo lugar entre agosto y diciembre de 2012. El análisis del corpus, que consta de 20 numeros de las revistas, se logrará mediante la aplicación de categorias del análisis crítica del discurso, con especial énfasis en herramientas sistematizadas por Theo van Leeuwen y Norman Fairclough.

Palabras clave: Justicia. Media. Discurso.

\section{JUSTIÇA, DIREITO E MEDIA}

Os tribunais de justiça foram vistos, durante séculos, como espaços sacralizados, profundamente distanciados dos cidadãos (SANTOS, 1996). Acreditava-se que essa seria a única maneira de assegurar a isenção dos magistrados e dos funcionários das cortes de justiça em face das pressões do exterior. Com a formação do Estado moderno e a adoção da transparência como valor indispensável para a democracia, os órgãos de administração da justiça procuraram aproximar-se mais da população, conservando, todavia, a ritualística que marca o modo de funcionamento da justiça até os nossos dias e cuja expressão maior está no modo como as coisas acontecem numa sala de audiências.

Por intermédio da cobertura jornalística do universo judicial, os meios de comunicação aparecem como fator determinante nesse processo de aproximação entre justiça e sociedade, introduzindo, porém, componentes que nem sempre figuram como positivos para a imagem da justiça perante a opinião pública. Quando reportam a realidade judicial, os media tendem a ressignificar concepções cristalizadas sobre a justiça, contribuindo para a sua dessacralização. Recorrendo a estratégias retórico-narrativas de humanização de atores judiciais, deixam evidentes as assimetrias entre o campo $^{1}$ da justiça e o campo dos media (COMMAILLE, 1994).

A relação dos media com a justiça é, de fato, marcada, em grande medida, por tensões e constrangimentos que aparecem por causa dos princípios e valores que constituem esses campos sociais, determinando a sua forma de funcionamento na sociedade (BOURDIEU,

\footnotetext{
${ }^{1}$ Fazemos uso do conceito de "campo" com o mesmo sentido que Pierre Bourdieu (2011) atribuiu ao conceito de "campo social". Para ele, um campo é um microcosmo com leis, agentes, instituições, valores e capitais simbólicos próprios e cuja autonomia em face de outros campos dependerá da sua maior ou menor capacidade de observar e traduzir o mundo segundo lógicas internas, ou seja, aquelas produzidas a partir do seu interior. Assim, um campo será tanto mais heterônomo quanto maior for a sua abertura e vulnerabilidade à interferência de lógicas alheias, ou seja, provenientes de outros campos.
} 
2001). Embora situados num mesmo espaço social e atuando, muitas vezes, sobre o mesmo caso - um crime contra a vida ou contra a probidade da Administração, por exemplo jornalistas e agentes judiciais não agem segundo os mesmos códigos de conduta. Na verdade, atuam com tempos, discursos, espaços e processualidades não apenas distintos entre si, mas, na larga maioria das vezes, funcionalmente incompatíveis (PRIOR, 2013; ARAÚJO, 2014).

Se os tribunais agem apenas quando instados, assumindo-se como organismos inertes e reativos e perseguindo a aplicação do devido processo legal ${ }^{2}$, os media, ao contrário, tendem a atuar de modo extremamente ativo na busca de informações que ajudem a endossar narrativas escandalosas, mesmo quando isso pressupõe a subversão de certas regras ${ }^{3}$. Torna-se claro, assim, que a relação entre o campo judiciário e o campo mediático assenta numa série de antagonismos "entre uma lógica de ação que preconiza a observância estrita de regras e procedimentos por parte da justiça e uma lógica mediática que privilegia a atualidade e enquadramentos que possibilitem o acesso e a rápida compreensão a largas camadas de público" (MACHADO; SANTOS, 2011, p. 157).

Ao refletir a problemática, o sociológico francês Jacques Commaille (1994) defende que o exercício da função de justiça, num tempo de sociedades altamente mediatizadas, está condicionado a uma partilha de poder entre a justiça e os meios de comunicação social extremamente complexa. Para o autor, os media fazem uso de um gigantesco poder simbólico e fático para apresentar ao público interpretações próprias sobre casos que estão sob o crivo do sistema judicial. Diante da mediatização de determinados casos judiciais, os tribunais se veem confrontados com "verdades mediáticas" sobejamente veiculadas que dão forma ao que Ray Surette (1998) chamou de "julgamentos mediáticos".

No quadro de uma reflexão mais ampla sobre as relações conflituosas entre os media e as instituições judiciárias nas sociedades contemporâneas, a presente reflexão pretende

\footnotetext{
${ }^{2}$ Terminologia oriunda do direito anglo-saxônico, que funciona como princípio fundamental do Estado de Direito, na medida em que pressupõe a garantia impreterível e total do atendimento de todos os direitos que o ordenamento jurídico prevê como passíveis de serem manejados pelas partes de um processo. É o que os americanos chamam de "due process of law". Moraes (2001, p.121) acrescenta que "o devido processo legal configura dupla proteção ao indivíduo, atuando tanto no âmbito material de proteção ao direito de liberdade, quanto no âmbito formal, ao assegurar-lhe paridade total de condições com o Estado-persecutor e plenitude de defesa [...]."

${ }^{3}$ Não são raras as vezes em que os media lançam mão de práticas questionáveis do ponto de vista jurídico, valendo-se da difusa noção de "interesse público" para as justificar. O caso clássico é o do vazamento de informações sigilosas, seja de processos que tramitam em segredo de justiça, seja de depoimentos no âmbito de investigações que ainda não possuem o estatuto de ação criminal, o que é expressamente proibido pela lei nacional.
} 
estudar um aspecto específico dessas relações, qual seja, o modo como o jornalismo constrói, em suas narrativas, a imagem dos juízes, os principais atores do sistema de justiça. Para tal, analisaremos o modo como as duas revistas de informação com maior circulação no país, as revistas Veja e Época, construíram a imagem dos juízes do Supremo Tribunal Federal durante os quatro meses de julgamento da Ação Penal 470, o processo do Mensalão, ocorrido entre agosto e dezembro de 2012. O corpus de análise é constituído por um total de 20 edições das revistas, veiculadas durante o julgamento, e que deram destaque aos magistrados.

Edições de Veja: 8/8/2012; 22/8/2012; 29/8/2012; 5/9/2012; 12/09/2012; $10 / 10 / 2012 ; 3 / 10 / 2012 ; 17 / 10 / 2012 ; 24 / 10 / 2012$.

Edições de Época: 6/8/2012; 8/10/2012; 19/11/2012; 15/10/2012; 29/10/2012; $10 / 9 / 2012 ; 27 / 8 / 2012 ; 3 / 9 / 2012 ; 8 / 8 / 2012 ; 27 / 9 / 2012 ; 17 / 9 / 2012$.

Estaremos atentos, especialmente, aos títulos, subtítulos e primeiros parágrafos dos textos, sem desconsiderar recortes discursivos, no interior da narrativa e nas capas das revistas, que sejam pertinentes à análise (ORLANDI, 1989). Também as imagens farão parte do escopo analítico, por entendermos que a dimensão imagética carrega significações correspondentes e complementares ao texto escrito. O escrutínio do material empírico será feito pela aplicação de categorias dos estudos críticos do discurso, com foco especial nas ferramentas que Theo van Leeuwen (1997) sistematizou em seu estudo sobre a representação dos atores sociais. Com o objetivo de identificar os modos de representar esses atores, van Leeuwen (1997) elaborou um copioso grupo de categorias sociológicas, assinalando as diferentes formas linguísticas através das quais essas representações se manifestam. Tendo em vista a abrangência desse mapa de categorias, selecionamos aquelas que permitem verificar a função que os participantes exercem nas narrativas jornalísticas. Assim, interessa saber quem é incluído e excluído das histórias, quem é representado como agente ou paciente das ações e de que maneira são identificados.

Do mesmo modo, a análise se inspira nos trabalhos do linguista inglês Norman Fairclough, em particular no seu conceito tridimensional de discurso. Fairclough, um dos expoentes da vertente crítica de análise do discurso, defende que qualquer discurso resulta da intersecção de três dimensões: um texto, uma prática discursiva e uma prática social. Para o autor, portanto, a compreensão de um discurso, cuja materialização ocorre em estruturas linguísticas a serem decompostas - ou seja, o texto -, só é possível se considerarmos as 
condições de produção do enunciado - a prática discursiva - e as imbricações que essas condições e o próprio texto final possuem com o tecido social onde o discurso foi produzido o que ele entende como prática social. Com base nessa formulação, recorreremos a duas categorias principais que o autor trabalha em seu modelo de análise do discurso: a lexicalização, que estuda as opções linguísticas do enunciador, e a interdiscursividade, que guarda relação com o conceito de intertextualidade, de Júlia Kristeva, e consiste na identificação das relações que o discurso estabelece com outros discursos.

\section{OS JUÍZES DO MENSALÃO EM NARRATIVAS DE VEJA E ÉPOCA}

Seguindo de perto as categorias de van Leeuwen (1997, p. 190), os juízes são referenciados, no discurso das revistas, de duas maneiras principais: por meio de estratégias discursivas de genericização e especificação. Segundo o autor, se no primeiro caso os atores sociais são referenciados como classes, como entidade plural, no segundo, esses mesmos atores são designados como indivíduos específicos e identificáveis. Centrando-nos na primeira estratégia, a tabela abaixo destaca um conjunto de títulos e subtítulos que demonstram a tendência para tratar os magistrados de forma genérica.

Tabela 1 - Titulação/Atores sociais como classes

\begin{tabular}{|c|c|}
\hline Veja & Época \\
\hline $\begin{array}{l}\text { O Supremo Tribunal Federal começa a julgar } \\
\text { os chefões do PT esta semana (Veja, } \\
3 / 10 / 2012 \text {, capa). }\end{array}$ & $\begin{array}{l}\text { Onze juízes em nome do Brasil (Época } \\
6 / 8 / 2012 \text {, capa). }\end{array}$ \\
\hline $\begin{array}{l}\text { O espetáculo da Justiça no STF (Veja, } \\
8 / 8 / 2012)\end{array}$ & $\begin{array}{l}\text { As decisões tomadas pelo Supremo no mensalão } \\
\text { revelam que os julgamentos de corruptos devem } \\
\text { ser mais duros daqui para a frente (Época, } \\
8 / 10 / 2012, \text { p. } 48 \text { ) }\end{array}$ \\
\hline $\begin{array}{l}\text { Os ministros ainda vão definir as penas dos } \\
\text { mensaleiros condenados. (Veja, 17/10/2012, p. } \\
\text { 72) }\end{array}$ & $\begin{array}{l}\text { Como os juízes do Supremo salvaram o } \\
\text { julgamento do mensalão - e o que muda no país } \\
\text { depois da sentença de prisão para José Dirceu. } \\
\text { (Época, } 19 / 11 / 2012 \text {, p. 40) }\end{array}$ \\
\hline $\begin{array}{l}\text { O Supremo começa a fazer história ao apontar } \\
\text { o caminho da prisão para políticos e } \\
\text { poderosos. Cinco mensaleiros foram } \\
\text { condenados e, pela veemência com que os } \\
\text { ministros repeliram a corrupção, a tradição de } \\
\text { impunidade pode estar no fim. (Veja, 5/9/2012, }\end{array}$ & $\begin{array}{l}\text { O exemplo que o Supremo Tribunal Federal dá } \\
\text { ao país ao condenar José Dirceu, José Genoino e } \\
\text { Delúbio Soares por corrupção (Época, } \\
15 / 10 / 2012 \text {, capa). }\end{array}$ \\
\hline
\end{tabular}


p. 79)

Fonte: elaboração própria.

Conforme se observa na Tabela 1, a figuração dos juízes é feita por meio dos nomes [O Supremo Tribunal Federal] ${ }^{4}$, [O Supremo], ou, dos nomes plurais [os juizes do Supremo], [os ministros]. Todas essas formas linguísticas conferem um sentido de coletividade aos atores judiciais, remetendo o leitor para uma certa homogeneidade nas decisões e no próprio andamento do julgamento. Ao mesmo tempo, diz-nos van Leeuwen (1997), tal estratégia de pluralização dos atores sociais contribui para a criação de um alto nível de consenso no discurso mediático - ideia que assume enorme importância na estruturação de um processo hegemônico orquestrado pelos media pela via do discurso. É também importante observar que os juízes aparecem sempre na condição de promotores da ação, isto é, em posição ativa, como constatamos nas construções verbais [começam a julgar], [vão definir], [começa a fazer], [salvaram], [ao condenar] — em contraposição aos réus, que aparecem, em todos os exemplos acima, como pacientes dessa mesma ação.

Ainda com base na ideia de consenso - que é central no conceito gramsciano de hegemonia $^{5}$-, o discurso das revistas é marcado por uma forte consensualidade quanto aos aspectos relacionados à atuação dos magistrados. Do ponto de vista semântico, o título [Onze ministros em nome do Brasil] evidencia uma tendência, identificada logo nas primeiras semanas de julgamento, que diz respeito à imputação mediática de uma grande responsabilidade aos juízes, não pelo julgamento em si, mas pelo resultado dele em face de expectativas que seriam de todo um país, como se vê pela inserção metonímica do nome [Brasil]. Essa estratégia é, aliás, vista por van Leeuwen (1997) como uma segunda forma de genericização dos atores sociais que ele chama de assimilação por agregação. Assim, a função agregadora do nome [Brasil], dado que engloba todos os brasileiros, age no sentido de legitimar o discurso da revista. Tanto é assim que essa legitimação é aprofundada na própria ilustração de capa daquela edição, como mostra a figura abaixo, em que um mapa do Brasil é construído com as faces dos magistrados.

\footnotetext{
${ }^{4}$ Os fragmentos entre colchetes dizem respeito à transcrição exata do discurso das publicações.

${ }^{5}$ Para uma discussão sobre a aplicação do conceito de hegemonia ao estudo dos media, cf. Hall (2016).
} 


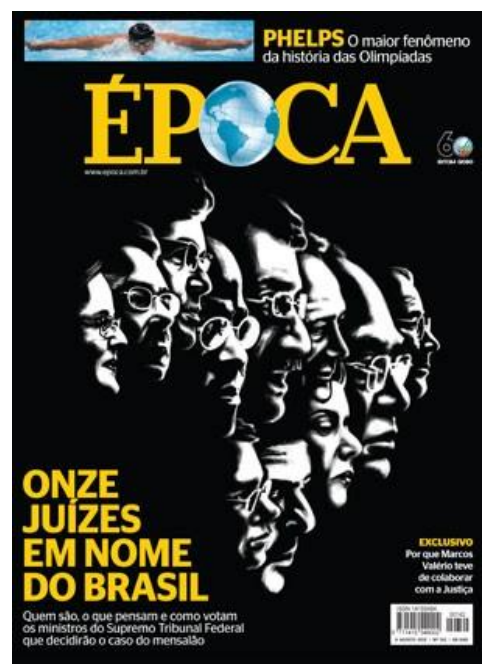

Figura 1 - Capa Época: "Onze juízes em nome do Brasil Fonte: revista Época, 6 ago. 2012

Essa ilustração confirma também uma tendência muito comum no discurso mediático que a análise crítica do discurso chama de interdiscursividade ou de intertextualidade constitutiva. Trata-se da apropriação, por parte do discurso principal, de certas propriedades e características de outros discursos. Nesse caso, note-se que a ilustração de capa da revista é baseada nos cartazes do clássico Julgamento em Nuremberg, filme de 1961, dirigido por Stanley Kramer, que narra a difícil missão do juiz Dan Haywood, designado para presidir o julgamento de autoridades alemãs, acusadas de crimes contra a humanidade pelas atrocidades cometidas durante a segunda guerra mundial. Essa narrativa cinematográfica fornece ao discurso em análise um frame, como mencionaria Goffman (1986), que age na construção discursiva da narrativa de Época mais de cinquenta anos depois. Isso ocorre, justamente, pela capacidade de os discursos dialogarem entre si, estabelecendo ligações intertextuais de contiguidade, como ocorre no exemplo acima.

Não obstante o valor histórico atribuído ao julgamento esteja relacionado com as características formais dele mesmo - o número de réus, as respectivas posições políticas de alguns, o tempo de duração e o tamanho do processo - , o discurso das revistas costuma fazer um paralelo entre a adjetivação "histórico" e as decisões condenatórias dos juízes. Nesse sentido, à medida que os réus vão sendo condenados, os enunciadores vão estabelecendo uma 
ligação de causalidade entre a atuação dos juízes na condenação dos acusados e o êxito do julgamento, como podemos notar em vários exemplos da Tabela 1. Esses mesmos exemplos deixam claro e explicam, de certo modo, o tom de grande positividade do discurso de Veja e Época em relação aos juízes do Supremo, como se observa no recorte discursivo abaixo, retirado de reportagem com título "A turma do corrompe, mas faz":

Agora, o Judiciário mostra sua força e independência no julgamento do mensalão. $\mathrm{O}$ valor simbólico da condenação de políticos poderosos é grande. (...). Ao longo de meses, os brasileiros aprenderam o nome dos integrantes do STF - e Joaquim Barbosa, relator do caso, passou a ser homenageado em manifestações públicas. Hoje, são os ministros do Supremo - e não algum partido político — os símbolos da ética no país (ÉPOCA, 29/10/2012, p.50)

Para além de confirmarem a adoção de uma abordagem bastante positiva em relação aos magistrados e, por consequência, ao próprio funcionamento do órgão máximo da Justiça brasileira, ao equipará-los a [símbolos da ética no país], aqueles que dão [referências éticas] aos brasileiros - novamente, o recurso a uma estratégia de agregação - ambos os excertos conduzem o leitor a uma segunda forma de referência aos magistrados: por meio de uma estratégia de especificação, eles são nomeados, ganham corpo, no discurso das revistas, por oposição às designações pluralizadas ou institucionalizadas. Essa constatação indica uma forte tendência para personificar a instituição judiciária, que se materializa em diferentes estratégias discursivas: o destaque às trivialidades; as abordagens biográficas; a topicalização da voz dos magistrados e a mediatização dos embates entre eles.

\section{O DESTAQUE Às TRIVIALIDADES}

Como defende Surette (1998), o discurso dos media sobre os dramas criminais é marcado por uma forte dose de dramatismo, à qual se junta uma peculiar tendência para o destaque aos detalhes insólitos que contribuem, em certos casos, para transformar esse tipo de narrativa em verdadeiros fait-divers, cuja figuração, na cobertura jornalística, tem o objetivo maior de despertar a curiosidade do público e vender o produto noticioso. Assim, uma das formas privilegiadas de personificação da instituição judiciária é o destaque conferido pelas revistas a determinadas trivialidades ao longo da cobertura, que são inseridas no texto jornalístico. 
Deixemos claro, no entanto, que o que consideramos trivial, neste contexto, não diz respeito ao detalhe em si (como, por exemplo, as dores do ministro Joaquim Barbosa), mas a sua figuração no discurso das publicações sobre as sessões e outras questões inerentes a um ritual judiciário de tamanha seriedade. Vejamos os exemplos da Tabela 2:

Tabela 2 - Destaque atribuído às trivialidades

\begin{tabular}{|c|c|}
\hline Veja & Época \\
\hline $\begin{array}{l}\text { (...) O ministro Joaquim Barbosa intercala } \\
\text { um estilo de vida simples com hábitos } \\
\text { sofisticados. Seu carro é um Honda Civic } \\
\text { fabricado em 2004. É amante de música } \\
\text { clássica, adora Zeca Pagodinho e prefere os } \\
\text { ternos importados e, controlado, consegue } \\
\text { economizar metade do que ganha ( } 26.600 \\
\text { reais) (...) (Veja, 10/10/2012, p.72). }\end{array}$ & $\begin{array}{l}\text { Laptops, e-mails e bilhetinho } \\
\text { Na comunicação entre os ministros do Supremo, } \\
\text { os métodos antigos se sobrepõem aos modernos. } \\
\text { Celso de Mello foi o primeiro a perceber que } \\
\text { papeizinhos dobrados estão a salvo dos } \\
\text { fotógrafos (Época, } 10 / 9 / 2012 \text {, p. } 40 \text { ) }\end{array}$ \\
\hline $\begin{array}{l}\text { Eliana Calmon é capaz de ficar horas e horas } \\
\text { falando de culinária. Sua especialidade mais } \\
\text { admirada, porém, é outra. Há dois anos, ela } \\
\text { assumiu o cargo de corregedora do Conselho } \\
\text { Nacional de Justiça (...). (Veja, 12/9/2012, p. } \\
\text { 17) }\end{array}$ & $\begin{array}{l}\text { (...) Na quinta-feira, ela [Rosa Weber] fugiu do } \\
\text { figurino preto-branco-bege que concorre com a } \\
\text { colega Cármen Lúcia, num desfile de tirar o } \\
\text { chapéu. Apareceu com um chiquérrimo tailleur } \\
\text { marrom, com grandes botões, por cima de uma } \\
\text { blusa verde (...). (Época, } 27 / 8 / 2012, \text { p.43) }\end{array}$ \\
\hline
\end{tabular}

Fonte: elaboração própria.

Como podemos observar, o carro e o estilo de vida do ministro Joaquim Barbosa, os gostos culinários da Corregedora, as roupas e sapatos de uma magistrada, ou a referência aos bilhetes trocados entre os juízes são detalhes que possuem certo ar de frivolidade e contribuem, na expressão do sociólogo francês Jacques Commaille (1994), não apenas para humanizar a figura do juiz, mas, também, pra banalizar o ato de julgar.

\section{A TOPICALIZAÇÃO DA VOZ DOS MAGISTRADOS}

Ao longo da cobertura, Veja e Época conferiram grande visibilidade às vozes dos magistrados, que aparecem como citações miméticas ora nos títulos, ora em posições de grande destaque. Na larga maioria das vezes, equivalem a leituras de sentenças, ou a opiniões diretamente dadas aos jornalistas. O discurso jornalístico abre-se, desse modo, ao discurso dos atores judiciais. Olhemos para os dois exemplos abaixo, retirados da Tabela 3: 
Trata-se de dois títulos, construídos com o recurso a citações miméticas referentes ao discurso de uma magistrada, a ministra Cármen Lúcia, e do Procurador-Geral da República, Roberto Gurgel. Esse tipo de estratégia é bastante comum no discurso dos media, que veem, na fala de atores sociais de grande proeminência, a forma ideal de fazer passar a sua própria opinião sobre os assuntos mediatizados. Por outro lado, não podemos desprezar a posição tópica - de proeminência - em que esses enunciados aparecem, tampouco as propriedades do elemento paratextual que os alberga - o título jornalístico - lugar nobre para o destaque de certas informações. Segundo van Dijk (2005), as informações colocadas em posição topicalizada têm uma função claramente cognitiva, na medida em que, ao sugerirem ser essa a informação de maior importância, contribuem para a formatação de "modelos de leitura preferenciais", que o leitor poderá aceitar ou não, em função de características individuais e de grupo. Outros exemplos podem ser observados na Tabela 3.

Tabela 3 - Topicalização da voz dos magistrados

\begin{tabular}{|l|l|}
\hline \multicolumn{1}{|c|}{ Veja } & \multicolumn{1}{|c|}{ Época } \\
\hline $\begin{array}{l}\text { "Agentes públicos que se deixam corromper e } \\
\text { particulares que corrompem são, corruptos e } \\
\text { corruptores, os profanadores da República, os } \\
\text { subversivos da ordem institucional, os } \\
\text { delinquentes, os marginais da ética do poder". } \\
\text { (Celso de Mello, Veja, 5/9/2012, p.78). }\end{array}$ \\
$\begin{array}{l}\text { "A cada desvio de dinheiro público, mais uma } \\
\text { criança passa fome, mais uma localidade fica } \\
\text { sem saneamento, sem mais um hospital, sem } \\
\text { leitos". (Luiz Fux, Veja, 5/9/2012, p. 78). }\end{array}$ & \\
\hline
\end{tabular}

Fonte: elaboração própria.

Um exemplo bastante emblemático nesse sentido é o principal artigo jornalístico publicado em Época, na edição de 15 de outubro de 2012, com o título [A voz ponderada do decano], que transcreve trechos substanciais de um voto condenatório do ministro Celso de Mello, após alguns parágrafos de exaltação das qualidades e da credibilidade do ator social. É curioso notar, porém, que as revistas não publicam, entre essas citações, trechos de sentenças absolutórias, designadamente, a do ministro Ricardo Lewandowski, que absolveu José Dirceu, o ex-ministro de Lula da Silva. Estamos aí diante de uma estratégia que van Leeuwen pontua 
como exclusão, ou seja, um determinado ator é suprimido da arena mediática, de forma a, e acrescentamos nós, manter o consenso na base do conceito gramsciano de hegemonia, essencial para o funcionamento da construção de climas públicos de opinião.

\section{MEDIATIZAÇÃO DOS EMBATES: A INDIVIDUALIZAÇÃO DOS MAGISTRADOS}

Algumas sessões do julgamento do mensalão foram marcadas por embates entre os ministros Joaquim Barbosa e Ricardo Lewandowski. A cobertura deu enorme importância a esses momentos, enfatizando a existência de disjunções interpretativas entre os magistrados em relação a alguns pontos do processo. É por isso que a mediatização desses momentos de tensão - e, também, de outros assuntos, como o suposto impedimento de um dos magistrados, pelo fato de ele ter trabalhado para um dos réus, antes de ser indicado para o STF — é fundamental para compreendermos as várias formas, encontradas pelas revistas, de personificar a instituição judiciária. Dessa forma, ao longo da cobertura foram sendo facultadas ao leitor diversas abordagens elucidativas do interesse mediático por tais momentos. Olhemos para os títulos e respectivos subtítulos consubstanciados na Tabela 4.

Tabela 4 - Titulação/Mediatização dos embates entre os magistrados

\begin{tabular}{|c|c|}
\hline Veja & Época \\
\hline $\begin{array}{l}\text { Tensão na corte } \\
\text { O presidente do Supremo Tribunal Federal diz } \\
\text { que o ministro Ricardo Lewandowski, revisor } \\
\text { do processo do mensalão, não queria que o } \\
\text { caso fosse julgado antes das eleições de } \\
\text { outubro (Veja, 22/8/2012, p.64) }\end{array}$ & $\begin{array}{l}\text { É agora que a jurupoca vai piar } \\
\text { De como Ricardo Lewandowski virou muso dos } \\
\text { advogados de defesa }- \text { e de como Joaquim } \\
\text { Barbosa, o muso da acusação, prometeu revidar } \\
\text { (Época, } 27 / 9 / 2012, \text { p. } 41 \text { ) }\end{array}$ \\
\hline $\begin{array}{l}\text { As duas versões da Justiça } \\
\text { Relator e revisor admitem que o mensalão foi } \\
\text { abastecido por dinheiro público, condenam os } \\
\text { primeiros réus, mas divergem quanto à } \\
\text { participação de petista (Veja, 29/8/2012, p. } \\
\text { 65). }\end{array}$ & $\begin{array}{l}\text { A arte de enervar o relator } \\
\text { De como Ricardo Lewandowski faz com que } \\
\text { Joaquim Barbosa, o careteiro, cumprimente a } \\
\text { testa com o nariz e, num volteio, enfie os cílios } \\
\text { pelos olhos (Época, } 17 / 9 / 2012, \text { p.52) }\end{array}$ \\
\hline
\end{tabular}

Fonte: elaboração própria.

No que diz respeito aos exemplos de Época, é interessante notar a carga semântica das opções lexicais feitas para discursivizar os embates entre relator e revisor, vistos como [muso da acusação] e [muso da defesa] respectivamente. Essa relação antagônica é também visível 
no discurso de Veja, que ao apontar a existência de [duas versões da Justiça] — sendo que o nome [Justiça], exercendo uma função de agregação no título, é, posteriormente, personificada nas figuras de ambos os juízes - enfatiza a existência de uma dualidade entre os membros da Suprema Corte. Cumpre salientar que o título [É agora que a jurupoca vai piar $]^{6}$, sendo essa uma expressão popular muito comum na linguagem cotidiana dos brasileiros, confere à narrativização desses embates um tom quase folclórico.

Além disso, diante da existência de duas versões - a do relator e a do revisor - o leitor perguntar-se-ia: quem está com a razão? Para responder à indagação, podemos assinalar a forma como os enunciadores se referiram aos magistrados. Repare-se que no título [A arte de enervar o relator], Lewandowski aparece na posição de quem provoca continuamente raiva no relator - fator explicitamente comprovado pelo significado conotativo da expressão [a arte de...]. Por outro lado, a tensão existente na Corte — de que fala o primeiro exemplo da tabela - é provocada pela discordância de Lewandowski de que o julgamento acontecesse no ano das eleições municipais ${ }^{7}$ - o que terá contribuído para a construção de um discurso muito mais disfórico em relação a Lewandowski do que a Barbosa. Relativos a Lewandowski, os excertos abaixo corroboram essa tendência, ao mesmo tempo em que ilustram a abundante recorrência a adjetivos para referenciar os juízes e, sobretudo no terceiro exemplo, a forte expressividade do sujeito-enunciador:

Entre suas singularidades, está também querer ser o melhor do melhor do mundo como provocador emérito - dos frios e calculistas - sem que pareça ser um provocador emérito dos frios e calculistas. (ÉPOCA, 17/9/2012, p. $52)$.

Na semana passada, os ministros começaram a julgar os réus acusados de formação de quadrilha. Pelo que se viu, essa etapa promete novas peripécias jurídicas do ministro Ricardo Lewandowski, que chegou ao STF no governo Lula por uma razão pitoresca - ter uma mãe muito amigo da então primeira-dama, Marisa Letícia. Lewandowski continuou demonstrando sua gratidão a Lula e ao PT por ter sido guindado a tão alto posto na hierarquia jurídica do país. (VEJA, 24/10/2012, 73).

\footnotetext{
${ }^{6}$ Os termos “jurupoca”, “jiripoca” ou "jerupoca”, originários da língua tupi guarani, são os nomes populares de um peixe nativo do Brasil. O peixe costuma nadar na superfície da água e emitir um som semelhante ao pio de um pássaro. Daí o surgimento da expressão popular "é hoje que a jurupoca vai piar", ou seja, algo está iminente e ocorrerá com grande força.

${ }^{7}$ Como se sabe, houve um sem-número de suposições, nos meios de comunicação e nos círculos políticos, acerca do possível impacto do julgamento do mensalão sobre o desempenho eleitoral dos candidatos petistas nas eleições de 2012, em caso de sentenças condenatórias para os membros do Partido dos Trabalhadores, réus no processo.
} 
Com efeito, o desempenho de Veja e Época relativamente a Lewandowski pode ser compreendido à luz da falta de alinhamento do juiz às expectativas mediáticas de condenação dos acusados. Por outro lado, os exemplos aqui comprovam a estratégia de diferenciação do ator social, nos moldes preconizados por van Leeuwen (1997), ou seja, a mediatização dos posicionamentos divergentes do ministro revisor o diferenciou dos demais membros do grupo de juízes. Para van Leeuwen (1997, p. 199), "a diferenciação diferencia explicitamente o ator social individual de um grupo de atores sociais de um ator ou grupo semelhante, criando diferença entre o "self" (próprio) e o "other" (outro), ou entre "us" (nós) e "them" (eles).

\section{AS ABORDAGENS BIOGRÁFICAS}

Outro ponto que confirma a tendência das revistas para personificar a instituição judiciária na imagem dos juízes tem relação com a criação de abordagens biográficas dos juízes. A edição de 6 de agosto da revista Época assume particular proeminência, nesse sentido, pela quantidade de textos publicados, cujo objetivo principal foi a construção de perfis, através dos quais o público poderia familiarizar-se com os perfilados. O próprio enunciador deixa isso claro ao enfatizar, na capa, que pretendia dizer ao leitor:

Quem são, o que pensam e como votam os ministros do Supremo Tribunal Federal que decidirão o caso do mensalão. (ÉPOCA, 6/8/2012, capa).

O subtítulo acima evidencia, justamente, a tentativa, por parte do enunciadordiscursivo, de estabelecer um perfil que sirva de base para inferências acerca das sentenças a serem proferidas. Dito de outra forma, é como se a publicação quisesse, desde já, encontrar, através de traços biográficos, indícios que prenunciassem a postura dos juízes frente ao processo em apreço. São curiosas, pois, as referências a decisões anteriores em julgamentos importantes, como a extradição de Cesare Battisti; a união homoafetiva; a lei da ficha limpa; as pesquisas com células-tronco embrionárias etc. Por outro lado, são dadas informações relativas às cidades onde nasceram os magistrados, às suas idades, às origens profissionais, às datas em que assumiram um lugar na Suprema Corte e ao respectivo Presidente da República que os indicou. (ÉPOCA, 6/8/2012).

Assim, é inequívoco o interesse da revista pelas peculiaridades dos magistrados. Incluímos, na Tabela 5, alguns títulos, seguidos dos respectivos subtítulos, que ajudam a ilustrar melhor a estratégia discursiva em questão. 
Tabela 5 - Titulação/Abordagens biográficas

\begin{tabular}{|l|l|}
\hline \multicolumn{2}{|c|}{ Época } \\
\hline Ayres Britto: O ex-amigo de Lula & Celso de Mello: O prestígio do decano \\
$\begin{array}{l}\text { Apesar de votos favoráveis ao governo e de ter } \\
\text { sido petista, ele frustrou o ex-presidente } \\
\text { (Época, 6/8/2012, p. 63). }\end{array}$ & $\begin{array}{l}\text { A voz do integrante mais antigo soa com } \\
\text { especial autoridade nos momentos de crise } \\
\text { (Época, 6/8/2012, p. 66). }\end{array}$ \\
\hline $\begin{array}{l}\text { Gilmar Mendes: Comedido, mas } \\
\text { impressionado }\end{array}$ & $\begin{array}{l}\text { Ricardo Lewandowski: Uma faca no pescoço } \\
\text { O ministro tem fama de ser brando, mas se de Lula, o ministro disse sentir-se } \\
\text { assustou com a natureza do mensalão (Época, } \\
\text { 6/8/2012, p. 67). }\end{array}$ \\
$\begin{array}{l}\text { pressionado em vários momentos do processo } \\
\text { (Época, 6/8/2012, p.69). }\end{array}$ \\
\hline
\end{tabular}

Fonte: elaboração própria

Os exemplos acima confirmam o efeito de humanização desses atores, intencional e mediaticamente criado. Vejamos que esta titulação contribui para criar uma imagem muito restrita dos julgadores, a partir de perspectivas específicas, como, por exemplo a amizade de alguns deles com réus e com o ex-presidente Lula. Isso terá contribuído para a construção de sentidos estereotipados perante o público, com a possibilidade de levantar suspeições sobre alguns julgadores, colocados numa posição de vulnerabilidade a pressões políticas.

\section{CONSIDERAÇÕES FINAIS}

Este trabalho se inscreve numa investigação mais ampla, que procura compreender as complexas relações entre os campos da justiça e dos media nas sociedades do nosso tempo. De modo mais específico, a reflexão e a análise aqui desenvolvidas quiseram entender essas relações por meio do escrutínio do discurso jornalístico das duas revistas semanais de informação com maior tiragem e circulação no Brasil, Veja e Época. O conjunto das categorias dos estudos críticos do discurso permitiu identificar uma série de estratégias discursivas de que as revistas se serviram para construir determinados sentidos sobre os julgadores do Mensalão, aos quais as mesmas publicações imputaram a responsabilidade de pr fim à cultura de impunidade no Brasil, numa tentativa de transformar o julgamento numa 
espécie de panaceia que, segundo o que se depreende do discurso analisado, seria capaz de transformar os erros e as incongruências estruturais da política brasileira.

A aplicação das categorias de Theo van Leeuwen (1997), oriundas de um estudo sobre a representação dos atores sociais, permitiu identificar duas grandes formas de nomeação dos juízes: por genericização, quando são tratados de modo coletivo, e por especificação, em que o enunciador dá ênfase à figura particular do ator. Percebemos que houve uma tendência acentuada para personificar a instituição judiciária na figura dos magistrados: eles aparecem como imagem da própria justiça e da lei. Esse trabalho de personificação da instituição judiciária ocorreu em quatro principais momentos, quais sejam, o destaque a trivialidades, a topicalização da voz dos magistrados, a mediatização dos embates e a ênfase em abordagens biográficas. Todos esses pontos funcionaram como estratégias discursivas que ajudaram, em certos momentos da cobertura, a trivializar o próprio ato de julgar e a banalizar, paradoxalmente, o julgamento, anunciado como "histórico", “o julgamento do século", pelos próprios enunciadores. $\mathrm{O}$ destaque a certas trivialidades também contribuiu para a operacionalização de um trabalho de humanização dos juízes que os despiu da aura sacralizada de que gozavam (COMMAILLE, 1994).

Por outro lado, o desempenho das revistas revelou a adoção de uma postura altamente prescritiva ou performativa, na qual foram dadas indicações de como os magistrados deveriam agir — “onze juízes em nome do Brasil”, como escreveu Época, num julgamento em que o "Supremo começa a fazer história ao apontar o caminho da prisão para políticos e poderosos", no dizer de Veja. Com efeito, as publicações transferiram para os ministros do Supremo Tribunal Federal a responsabilidade pela transformação de um problema estrutural secular no país. Ao condenarem figuras de vulto na política nacional, indo, pois, ao encontro das expectativas previamente condenatórias dos meios, os juízes são alçados à categoria de heróis nacionais, com particular destaque para o papel do relator do caso, ministro Joaquim Barbosa, cuja representação analisamos em outro momento (ARAÚJO, 2014).

Como se procurou demonstrar, no momento da cobertura, os meios de comunicação em análise construíram uma imagem bastante positiva dos juízes do Mensalão, situando-os no patamar de heróis da nação. Em nossa opinião, agiram assim porque as decisões judiciais coincidiram com as expectativas mediáticas de condenação dos acusados. O julgamento, porém, não se encerrou em dezembro de 2012, quando foram proferidas as últimas sentenças e ditadas as respectivas penas. Nos dois anos seguintes, diferentes recursos dos réus foram julgados, desencadeando a diminuição de penas e mesmo a absolvição de alguns 
anteriormente condenados, como foi o caso de José Dirceu, José Genoino e Delúbio Soares, que conseguiram reverter a condenação pelo crime de formação de quadrilha. Em investigações futuras, portanto, seria interessante inspecionar a performance das mesmas publicações num contexto em que o mesmo tribunal contrariou expectativas mediáticas, adotando uma postura diferente da prescrita pelos meios de comunicação mainstream.

\section{REFERÊNCIAS}

ARAÚJO, B. B. de. Justiça, Media e Espaço Público: a cobertura do julgamento do Mensalão em Veja e Época, Saarbrücken: Novas Edições Acadêmicas, 2014.

BOURDIEU, P. (2011 [1989]). O Poder Simbólico. Lisboa: Difel.

COMMAILLE, J. L'exercice de la fonction de justice comme enjeu de pouvoir entre Justice et médias. Droit et Société, 26. Paris: LGDJ, pp. 11-18, 1994.

CUNHA, I. F. Análise dos Media. Coimbra: Imprensa da Universidade de Coimbra, 2012.

FAIRCLOUGH, N. Media discourse. London: Edward Arnold, 1995.

. Discurso e Mudança Social. Brasília: Editora Universidade de Brasília, 2001.

GANS, H. J. Deciding What's News. A Study of CBS Evening News, NBC Nightly News, Newsweek and Time. Medill Visions of the American Press, 2004 [1979].

GOFFMAN, E. Frame Analysis. Philadelphia: Pennsylvania University Press, 1986.

GOLDING, P.; ELLIOTT, P. Making the News. London: Longman, 1979.

HALL, S. et al. A produção social de notícias: o 'mugging' nos media. In: TRAQUINA, Nelson. (org.), Jornalismo: Questões, Teorias e Estórias. Lisboa: Vega, pp. 224-248, 1999.

KELLNER, D. Megaspectacle: The O. J. Simpson murder trial. In: Media Spectacle. London: Routledge, pp. 93-125, 2003.

MACHADO, H.; SANTOS, F.. Direito, Justiça e Média: Tópicos de Sociologia. Porto: Edições Afrontamento, 2011.

. Crime, Drama e Entretenimento. O caso Maddie e a Meta-Justiça Popular na Imprensa Portuguesa. Oficina CES nº. 310, 2008.

MOLOCH, H; LESTER, M. As Notícias como procedimento intencional: acerca do uso estratégico e acontecimentos de rotina, acidentes e escândalos. In: TRAQUINA, Nelson. (org.), Jornalismo: Questões, Teorias e Estórias. Lisboa: Vega, pp. 34-51, 1999. 
MORAES, A. de. Direito constitucional. 10. ed. São Paulo: Atlas, 2001.

ORLANDI, E. P. Vozes e contrastes: Discurso na cidade e no Campo. São Paulo: Editora Cortez, 1989.

PRIOR, H. A Comunicação Social e o Discurso Judiciário. Derecom - Revista Online Especializada en Derecho de la Comunicación, 14:118-130, 2013.

SANTOS, B. S. et all. Os tribunais nas sociedades contemporâneas. O caso Português. Porto: Edições Afrontamento, 1996.

SCHLESINGER, P. Putting reality together. BBC News. London: Constable, 1978.

SURETTE, R. Media Trials. Journal of Criminal Justice, v.17. Florida International University, pp. 293-308, 1989.

Media, Crime and Justice: Images and Realities. Belmont CA:

Thomson/Wadsworth, 1998.

TRAQUINA, N. Jornalismo: questões, teorias estórias. Lisboa: Vega, 1999.

TRAQUINA, N.; SILVA, M. T., CALADO, V.. A Problemática da SIDA como Notícia. Lisboa: Livros Horizonte, 2007.

WOLF, M. Teorias da comunicação. Lisboa: Editorial Presença, 2009.

Original recebido em: 25 de outubro de 2016

Aceito para publicação em: 22 de dezembro de 2017

Bruno Bernardo de Araújo

Professor no curso de Jornalismo da Faculdade de Comunicação e Artes da Universidade Federal de Mato Grosso. Doutor em Comunicação pela Universidade de Brasília. Mestre e graduado em Jornalismo pela Universidade de Coimbra. Integra o Núcleo de Estudos sobre Mídia e Política e o Grupo de Pesquisa Cultura, Mídia e Política, ambos da Universidade de Brasília. É, ainda, colaborador do Grupo de Pesquisa Comunicação, Jornalismo do CEIS/20/Universidade de Coimbra e do Center for Research in Communication, Information and Digital Culture da Universidade Nova de Lisboa.

\section{(@) $\Theta \odot$}

Esta obra está licenciado com uma Licença

Creative Commons Atribuição-NãoComercial-CompartilhaIgual 4.0 Internacional 